\title{
APLICAÇÃO DA TEORIA DAS RESTRIÇÕES E DO INDICADOR DE EFICIÊNCIA GLOBAL DO EQUIPAMENTO PARA MELHORIA DE PRODUTIVIDADE EM UMA LINHA DE FABRICAÇÃO
}

\section{APPLICATION OF THE THEORY OF CONSTRAINTS AND THE OVERALL EQUIPMENT EFFECTIVENESS FOR PRODUCTIVITY IMPROVEMENT IN A MANUFACTURE LINE}

\author{
Artur Henrique Moellmann ; Alexandre Saul Albuquerque ${ }_{4}^{2}$; José Luiz Contador ; Fernando \\ Augusto Silva Marins \\ Mectron Eng. Ind. e Com. - São José dos Campos - Brasil artur@mectron.com.br \\ AMBEV - Manaus - Brasil fmasa@ambev.com.br

\begin{abstract}
Resumo
O trabalho apresenta e utiliza o conceito de Índice de Eficiência Global do Equipamento (OEE Overall Equipement Effectiveness), aliado à Teoria das Restrições (TOC - Theory of Constraints) $e$ técnicas de Kaizen, como ferramentas de análise e para a escolha de ações de melhoria em linhas de produção. A metodologia foi implementada numa fábrica de motores de uma multinacional do setor automobilístico, localizada na região do Vale do Paraíba, interior de São Paulo. Além da evolução dos indicadores de desempenho das operações, é apresentada também a evolução da produção de toda a linha de fabricação. Os bons resultados obtidos indicam claramente a validade do uso conjunto das referidas técnicas da Engenharia de Produção.
\end{abstract}

Palavras-chave: Indicador de Eficiência Global do Equipamento, Teoria das Restrições, Kaizen.

\section{Introdução}

Um dos grandes desafios enfrentados pelo meio industrial baseia-se na eficiente e correta utilização dos recursos disponíveis para a produção, sejam estes operacionais ou humanos. A necessidade da transformação de produtos em elevada escala para viabilizar a existência da empresa, em conjunto com a constante exigência por redução de custos e investimentos, valoriza cada vez mais quaisquer métodos e conceitos que conduzam a uma utilização eficaz dos recursos alocados nas unidades fabris. Estudos sobre a maximização da utilização da capacidade produtiva 
instalada têm sido constantemente desenvolvidos, visando principalmente à redução de custos e aumento de capacidade em curto prazo.

A disponibilidade de um equipamento representa o tempo total disponível em que a máquina realmente pode ser utilizada para converter a matéria-prima em produto final, ou seja, agregando valor ao produto. Com o intuito de analisar a evolução da produtividade dos equipamentos em questão, utilizou-se o Índice de Eficiência Global do Equipamento - OEE (Overall Equipment Effectiveness), índice comumente utilizado na indústria e que engloba indicadores de qualidade, eficiência e disponibilidade (HANSEN, 2002).

A análise deste indicador apresenta uma imediata idéia da capacidade da linha como um todo, se for conhecida a capacidade bruta de produção das máquinas. Trata-se de indicador extremamente útil também para a análise das operações gargalo, ou seja, aquelas que restringem a produção de toda a linha de fabricação.

O cálculo do indicador de eficiência OEE é fundamental para uma análise precisa e para um adequado direcionamento de ações visando a quebra dos gargalos da linha de fabricação. Para isso, tornam-se de muita importância todos os detalhes que constituem o levantamento do indicador OEE, como, por exemplo, a correta tomada de tempos de ciclo das operações para determinação de sua capacidade bruta de produção.

O presente trabalho enfoca as ações propostas e realizadas sobre equipamentos dispostos em uma linha de usinagem de uma grande multinacional do setor automobilístico, localizada na região do Vale do Paraíba, interior do estado de São Paulo. Trata-se de ações de engenharia visando à contínua evolução e incremento da produção, sem, no entanto, exigir elevados investimentos, aplicando-se perfeitamente os conceitos da Teoria das Restrições (Theory of Constraints - TOC), introduzida por GOLDRATT (1997) e da Melhoria Contínua (Kaizen) conforme descrito por MAURER (2004).

Aqui, apresentam-se as ações implementadas sobre a linha de usinagem de blocos de motores de combustão interna, surgidas com o intuito de incrementar a disponibilidade do equipamento, ou reduzir seu tempo de ciclo, e explicita-se a evolução dos indicadores de desempenho das operações envolvidas. Além disso, apresenta-se também a evolução da produção de toda a linha de fabricação.

Assim, o objetivo principal deste estudo consistiu em mostrar a relevância e a vantagem na utilização do indicador de Eficiência Global do Equipamento - OEE, em conjunto com a TOC e o Kaisen, para direcionar ações de melhoria em linhas de fabricação. Isso foi exemplificado por meio de uma aplicação numa empresa do setor automobilístico onde foram melhorados os valores de capacidade líquida das máquinas operatrizes da linha de usinagem de blocos de motores, o que permitiu ganhos na produtividade geral da linha de fabricação de motores. 
O artigo está estruturado como se segue. A seção 2 apresenta os conceitos fundamentais no estudo de produtividade e eficiência em linhas de fabricação, bem como expõe detalhes do indicador de Eficiência Global do Equipamento - OEE, da TOC e Kaisen. Na seção 3 está descrito o estudo de caso, detalhando-se o que foi proposto como ação de melhoria em alguns dos equipamentos da linha de fabricação estudada. Por fim, apresentam-se algumas conclusões e a bibliografia consultada.

\section{Fundamentos teóricos}

\subsection{Linha de produção}

O conceito de linha de produção foi, e continua sendo, um dos pilares fundamentais para o desenvolvimento de toda a indústria. Permitiu uma revolucionária evolução em todas as áreas da engenharia, a popularização de produtos, que eram então inalcançáveis à maioria da população, o gigantesco crescimento de muitas indústrias e a criação de um mercado capitalista de proporções mundiais.

A linha de produção proporciona a possibilidade de fabricação de produtos em elevadas quantidades, a custo individual extremamente baixo, utilizando-se para isso a reprodutibilidade de operações, em detrimento da sua variabilidade. Propiciam-se grandes volumes de produção, porém em um número extremamente restrito de opções de produtos ao consumidor. Este conceito foi implementado pela primeira vez por Henry Ford.

O conceito fundamental da linha de produção está na disposição linear de operações subseqüentes, onde a realização de uma operação depende da conclusão da operação anterior. Desta maneira, realizam-se diversas operações paralelamente, em uma grande quantidade de produtos, permitindo-se uma elevada produtividade na linha. A dedicação exclusiva de pessoas e equipamentos para realizar apenas uma operação é sempre a mesma, limitando as opções de variabilidade na linha. Hoje em dia, o conceito de linha de produção vem sofrendo atualizações e renovações, visando oferecer ao consumidor uma gama de maior variedade nos produtos, sem, entretanto, comprometer a produtividade da indústria.

Em muitos casos, as linhas são subdivididas em células de produção, ou células de manufatura, onde cada área da planta, denominada célula, será responsável pela produção de um sub-componente do produto, para que estes sejam posteriormente unidos. Entretanto, mesmo no interior das células, encontram-se operações subseqüentes, onde a conclusão com sucesso de uma delas é fator fundamental para a execução das demais. Deste modo, este estudo sobre produtividade em linhas de produção pode perfeitamente ser aplicado às células de manufatura, ou qualquer outra disposição na indústria, onde exista uma seqüência de operações de beneficiamento do produto. 
Para um aproveitamento eficiente de toda a capacidade de uma linha de produção é de fundamental importância um gerenciamento eficaz dos recursos disponíveis, evitando subaproveitar o potencial instalado na indústria. Um dos objetivos deste estudo foi analisar e discutir um meio adequado para orientar o gerenciamento da linha, oferecendo uma ferramenta eficaz para direcionar decisões que acarretassem em melhor aproveitamento dos recursos disponíveis para produção (CONTADOR, 1997).

Segundo SLACK et al. (2002), a maioria das organizações precisa decidir sobre o tamanho (em termos de capacidade) de cada uma de suas instalações. Uma empresa de ar condicionado, por exemplo, pode operar fábricas com capacidades individuais (para mix normal de produtos) de 800 unidades por semana. Com níveis de atividade abaixo deste, o custo médio de produção de cada unidade aumentará porque os custos fixos da fábrica estarão sendo cobertos por um menor número de unidades produzidas.

Os custos totais de produção da fábrica têm alguns elementos fixos - estes existem independentemente da quantidade produzida. Outros custos existentes são variáveis - são os custos que a fábrica tem para cada unidade produzida. Juntos, os custos fixos e variáveis abrangem o custo total de qualquer nível de output. Dividindo esse custo pelo nível de output, tem-se o custo teórico médio de produção de unidades para aquela taxa de output. Entretanto, a curva de custo médio real pode ser diferente desta linha por diversas razões:

- Os custos fixos não são todos incorridos de uma só vez quando a fábrica começa a operar. Em vez disso, ocorrem em vários momentos (chamados "pontos de quebra" de custos fixos) à medida que o volume aumenta. Isso torna mais descontínua e suave a curva teórica de custo médio;

- Os níveis de produção podem ser aumentados acima da capacidade teórica da planta, por meio do uso de horas-extras, por exemplo, ou sub-contratando temporariamente alguma parte do trabalho;

- Pode haver penalizações em custo menos óbvias ao operar uma fábrica em níveis próximos ou acima de sua capacidade normal. Por exemplo, longos períodos de horasextras podem reduzir os níveis de produtividade e ter maior custo com pagamentos extras ao pessoal; ou operar a planta durante longos períodos com tempo reduzido de manutenção pode aumentar a probabilidade de quebras (interrupções).

Assim, os custos médios começam a aumentar depois de um ponto que, em geral, será menor do que a capacidade teórica da planta. Unidades com grande capacidade produtiva também apresentam algumas desvantagens quando a capacidade da operação está sendo alterada para 
atender a uma demanda que está mudando (SLACK et al., 2002). O uso mais comum do termo capacidade é no sentido estático, como o volume físico de um recipiente ou o espaço de um edifício. Esse significado da palavra às vezes também é usado por gerentes de produção.

Embora essas medidas de capacidade descrevam a escala dessas operações, não refletem suas capacidades de processamento. Para fazer isso, deve-se incorporar a dimensão adequada de tempo para o uso dos ativos. Como exemplo, uma empresa farmacêutica trata do nível de produção que pode ser conseguido usando os reatores de 1.000 litros; se a cada hora pode ser produzida uma batelada de produtos padrão, a capacidade de processamento planejada pode ser equivalente a 24.000 litros por dia; se a reação demorar quatro horas e forem necessárias duas horas para limpeza entre as bateladas, o reator somente poderá produzir 4.000 litros por dia. Logo, a definição de capacidade de uma operação é o máximo valor adicionado em um determinado período de tempo que o processo pode realizar sob condições normais de operação (SLACK et al., 2002).

Muitas organizações operam abaixo de sua capacidade máxima de processamento, seja porque a demanda é insuficiente para preencher completamente sua capacidade, seja por uma política deliberada, de forma que a operação possa responder rapidamente a cada novo pedido. Com freqüência, entretanto, as organizações encontram-se com algumas partes de suas operações funcionando abaixo de sua capacidade, enquanto que outras estão funcionando em sua capacidade máxima (SLACK et al., 2002).

Tendo definido a capacidade em longo prazo, os gerentes de produção devem decidir como ajustar a capacidade da operação no médio prazo. Isso normalmente envolve uma avaliação da demanda futura em um período de 2 a 18 meses, durante o qual o volume de produção pode variar, por exemplo, alterando o número de horas que os equipamentos são usados.

$\mathrm{Na}$ prática, entretanto, poucas previsões são exatas, e a maioria das operações também precisa responder às mudanças na demanda que ocorrem em um período de tempo menor. Dessa forma, os gerentes de produção também devem fazer ajustes de capacidade de curto prazo que lhes permitam flexibilizar o volume produzido por um curto período, seja com base em previsões ou sem aviso.

A característica importante do planejamento e controle da capacidade, como está sendo abordado aqui, é a que visa definir os níveis de capacidade no médio e curto prazos em termos agregados. Isto é, tomar decisões de capacidade amplas e gerais, mas não se preocupar com todos os detalhes dos produtos e serviços individuais oferecidos. Logo, políticas agregadas assumem que o mix de diferentes produtos e serviços permanecerá relativamente constante durante o período de planejamento. 


\subsection{Teoria das Restrições (TOC) e Lean Manufacturing}

A Teoria das Restrições (TOC) consiste em um sistema de programação de produção criado a partir da análise e reestruturação das restrições encontradas na linha. Fundamenta-se em uma seqüência de passos a serem implementados na empresa, onde o planejamento, a execução e o controle são realizados através do Gerenciamento das Restrições, baseando-se no pressuposto de que se deve atuar nas causas das restrições que impedem o sistema de alcançar sua principal meta, que é a maximização dos ganhos e da rentabilidade do sistema como um todo (APICS Dictionary, p. 85) (COX III e SPENCER, 2002).

"A Restrição é qualquer elemento ou fator que impede que um sistema conquiste um nível melhor de desempenho no que diz respeito a sua meta. (As restrições podem ser físicas, como por exemplo, um equipamento ou a falta de material, mas elas podem ser também de ordem gerencial, como procedimentos, políticas e normas) (APICS Dictionary, p. 15)" (COX III e SPENCER, 2002).

A técnica que permite facilmente compreender o ambiente e planejar o processo de implementação e retro-alimentação da TOC denomina-se "O Método de Focalização em 5 Etapas" (APICS Dictionary, p. 31) (COX III e SPENCER, 2002) e consiste em:

a) 1 ${ }^{\text {a }}$. Etapa: Identificar a Restrição do sistema, onde o recurso de menor capacidade define a capacidade máxima de todo o sistema. Em outras palavras, significa que alimentar a Restrição com menos implica em perda de oportunidade e/ou vendas, e alimentá-la com mais não resulta em maior saída;

b) 2a . Etapa: Decidir como explorar a Restrição do sistema. Ou seja, para maximizar o desempenho de todo o sistema é necessário, portanto, tirar o máximo proveito possível do recurso que o restringe;

c) $3^{\text {a }}$ Etapa: Subordinar todo o sistema ao que foi decidido na $2^{\mathrm{a}}$ etapa;

d) 4a Etapa: Elevar a Restrição do sistema;

e) $\mathbf{5}^{\mathbf{a}}$ Etapa: Voltar à $1^{\mathrm{a}}$ etapa se a restrição for eliminada em algum passo anterior e não permitir que a inércia atue neste processo.

Define-se por gargalo (COX III e SPENCER, 2002) aquela operação realizada em um dado equipamento que apresenta a menor capacidade de produção líquida de bens (peças, serviços, etc), restringindo desta maneira a produção de toda a linha. Se existem diversas operações em seqüência, com tempos de ciclo diferentes, aquela ou aquelas operações (pode existir mais de um gargalo em uma linha ou sistema produtivo) de maior ciclo limitam a capacidade produtiva e, deste modo, geram ociosidade de capacidade nas demais operações. 
Uma vez definidos os gargalos na linha, orientam-se as ações para reduzir o ciclo dessas operações e aliviar a carga de trabalho no equipamento gargalo, aumentando sua capacidade de produção. Ao se fazer isto, provavelmente outro equipamento se tornará gargalo. Combate-se então esse novo gargalo, aumentando novamente a capacidade da linha. Para evitar interrupções, ou subutilização de determinadas operações gargalo, são utilizados os chamados pulmões na linha. Pulmões são estoques de peças em produção, inseridos em locais estratégicos entre as operações, estabelecendo as proteções contra os atrasos de abastecimento para a próxima operação gargalo, compensando eventuais desfalques causados pela operação anterior. Desta maneira, garante-se o funcionamento ininterrupto de todas as operações da linha de produção.

Com conceitos opostos às necessidades de manutenção de pulmões na linha, surgiu a Manufatura Enxuta (Lean Manufacturing), onde a existência de inventário entre as operações é reduzida ao mínimo, não se permitindo a estocagem de peças entre operações (HOBBS, 2003). Trata-se do conceito de fluxo de uma peça (one piece flow), onde, em qualquer ponto da linha de produção, e a qualquer momento, a peça a ser produzida está fluindo, na velocidade exata para atender às demais operações. Nem tão veloz, que cause estoque entre operações, nem tão lentamente, que cause falta de peças na operação seguinte. Trata-se de situação rara no meio industrial, pois sua viabilização depende da existência de máquinas de igual capacidade, disponibilidade e eficiência, sem paradas não programadas, apresentando iguais níveis de qualidade, com operadores de igual ritmo, etc.

\section{3 Índice de Eficiência Global do Equipamento}

\section{O Índice de Eficiência Global do Equipamento (OEE - Overall Equipment Effectiveness)} é uma ferramenta importante na linha de produção para se conhecer o desempenho de seus equipamentos. Com um adequado tratamento de dados, verifica-se a evolução do índice, o reflexo das ações implementadas nos equipamentos e eventuais falta de peças ou re-trabalhos, permitindo assim uma análise crítica e detalhada sobre os processos de produção (http://www.oee.com/fasttrack_oee.html).

Para se realizar o correto cálculo do indicador de eficiência global do equipamento e prover as informações adequadas para direcionar ações de melhoria nos equipamentos, são recomendados alguns procedimentos, de maneira que as perdas de produção sejam estratificadas e registradas, possibilitando uma posterior análise pelos engenheiros da linha de produção.

Todas as perdas de produção (paradas de linha) devem ser registradas, anotando-se a data, hora e motivo da parada e o tempo durante o qual a mesma afetou a produção. Desta maneira, é possível ao final de um período determinado (uma semana, um mês, ou qualquer outro, a critério da 
empresa) realizar uma estratificação das perdas, visualizando-se desta maneira os fatores que mais afetaram a produtividade deste equipamento.

Para análise da capacidade líquida de produção da máquina é preciso antes conhecer a capacidade bruta de produção $\left(\mathrm{C}_{\mathrm{b}}\right)$, definida como aquela capacidade que seria alcançada caso não existisse quaisquer tipos de perdas durante todo o tempo de operação do equipamento. A capacidade bruta da máquina, em peças por hora, pode ser calculada por:

$$
\mathbf{C}_{\mathbf{b}}=\mathbf{3 6 0 0} / \mathbf{T}_{\mathbf{e}} \text {, onde } \mathrm{T}_{\mathrm{e}} \text { é o tempo de ciclo da operação, em segundos. }
$$

O cálculo do indicador OEE envolve três fatores: disponibilidade, eficiência e qualidade. A disponibilidade é dada pela porcentagem do tempo em que o equipamento é utilizado efetivamente em atividade produtiva. Essa medida aponta todas as perdas por avarias, troca de ferramentas, manutenção preventiva e corretiva, e quaisquer outras paradas de produção. A eficiência da máquina ou da operação, segundo fator do indicador OEE, é dada pela relação percentual entre a produção real e a produção padrão, ou ainda, pela relação percentual entre o tempo padrão da operação e seu tempo real de execução. E a qualidade é medida pela porcentagem de peças produzidas pela máquina que cumpriu todos os requisitos e exigências de qualidade.

O indicador OEE é calculado por:

\section{$\mathrm{OEE}=$ eficiência $\mathrm{x}$ disponibilidade $\mathrm{x}$ qualidade.}

Conhecendo-se o OEE e a $\mathrm{C}_{\mathrm{b}}$, obtém-se a capacidade líquida $\left(\mathrm{C}_{1}\right)$ :

$$
\mathrm{C}_{1}=\mathrm{C}_{\mathrm{b}} \times \mathrm{OEE}
$$

A capacidade líquida de produção é a quantidade de peças que a operação vai efetivamente produzir. Obviamente, quanto mais próximo de 1 (100\%) for o índice OEE, mais eficiente será a linha. Empresas que aplicam com freqüência os conceitos de melhoria contínua - Kaizen (http://www.gembakaizen.com ) conseguem obter índices OEE entre 85 a 90\%.

A determinação do gargalo deve partir de um estudo que se inicia na identificação das operações, definindo claramente aquelas que agregam valor e aquelas que não agregam valor. Em grande parte dos casos, a operação gargalo é definida de acordo com a capacidade bruta de produção da máquina, ou sua capacidade líquida, se descontadas as perdas apresentadas. Aqui, as operações gargalo foram determinadas de duas maneiras distintas, de acordo com a restrição imposta por ela à linha. Havia tanto as operações-gargalo que apresentavam restrições de 
capacidade como as operações que apresentavam restrições de disponibilidade. Com freqüência, uma mesma operação apresentava restrição de disponibilidade e capacidade.

A divulgação dos equipamentos que apresentam restrições de disponibilidade deu-se simplesmente por opção do Departamento de Engenharia, por considerar-se que, desta maneira, direcionavam-se com maior facilidade ações para que as restrições fossem superadas. Para efeito de cálculo da capacidade da linha, foi considerada operação gargalo aquela que apresentasse a menor capacidade líquida de produção (capacidade bruta multiplicada pelo indicador OEE).

$\mathrm{Na}$ empresa estudada, o grande objetivo do acompanhamento dos indicadores de eficiência OEE foi à orientação dos esforços visando o incremento da produção nas operações e a conseqüente melhoria na linha de fabricação, que proporcionaram um desempenho superior destas linhas - que é o conceito de Melhoramento Contínuo (Kaizen). Na realidade, em geral, a busca pelo desempenho ótimo possui cinco objetivos: qualidade, velocidade, confiabilidade, flexibilidade e custo (CONTADOR, 1997).

O Melhoramento Contínuo adota uma abordagem de melhoria gradual e ininterrupta de desempenho que presume mais e menores passos. No melhoramento contínuo, não é a taxa de melhoramento que é importante, mas sim o momento em que ele ocorre (SLACK et al. 2002).

Depois de ter sido medido o desempenho de uma operação, em nosso caso pelo OEE, faz-se necessário um julgamento qualitativo (bom, mau ou desempenho indiferente). Há diversas formas de se fazer isso. Cada uma delas envolve comparação do nível de desempenho atualmente atingido com algum tipo de padrão. Quatro tipos de padrões são comumente utilizados: padrões históricos, padrões de desempenho meta, padrões de desempenho concorrência e padrões de desempenho absolutos. Neste trabalho os padrões históricos para análise foram utilizados.

\section{Estudo de caso numa indústria do setor automobilístico}

Este estudo teve como objeto as operações de usinagem em uma indústria automobilística, onde quatro dos componentes do motor são ali fabricados: bloco do motor, cabeçote, biela e virabrequim. Estes componentes são usinados dentro da empresa a partir de materiais brutos fornecidos por terceiros. A eficiência e a adequada utilização dos equipamentos existentes nas linhas de produção dentro da fábrica são fundamentais para a obtenção dos níveis desejados de fabricação de motores.

Então, os esforços foram concentrados no sentido de maximizar a produção destes componentes acima citados, oferecendo a possibilidade da fábrica aumentar sua produção de motores prontos para a montagem de veículos, ou para sua venda, utilizando-se da melhor maneira possível os recursos disponíveis na indústria e reduzindo os custos globais de fabricação do motor. 
Foram coletados dados de produtividade de blocos, em diversos pontos e máquinas da linha de usinagem que são divididas em diversas operações; realizadas por uma ou mais máquinas, cada qual consistindo basicamente em uma transformação no material bruto.

Optou-se por analisar linhas de usinagem da fábrica de motores principalmente devido ao fato de tratar-se de linhas cuja utilização atual estava próxima do nível de sua capacidade projetada. As ações de melhoria possuiram duas diferentes finalidades: melhoramento do tempo de ciclo da operação e incremento da disponibilidade.

Deve-se observar que ações visando melhoramento do tempo de ciclo eventualmente mantêm inalterado o índice OEE, elevando, contudo, a capacidade de produção bruta da linha e a capacidade de produção líquida. Já as ações direcionadas ao incremento da disponibilidade possuem ação direta sobre o OEE, mantendo inalterada a capacidade bruta elevando, entretanto, a capacidade de produção líquida.

Cinco operações de usinagem foram estudadas, as quais foram denominadas pelos números: $320 ; 325 ; 330 ; 350$ e 370. Historicamente, o equipamento crítico da linha era aquele responsável pela Operação 370. Tratava-se de um centro de usinagem, responsável pela realização de uma série de furos no bloco para a posterior fixação de outros componentes do motor, além de permitir o fluxo de óleo lubrificante e possuía baixos valores de disponibilidade, ocasionando a parada na linha.

A existência de estoques no ponto de uso era limitada, sendo o abastecimento realizado de acordo com a utilização do mesmo. Quando o estoque no ponto de uso aproximava-se do fim, o operador do equipamento acionava o responsável pelo abastecimento da linha, que repunha o material, evitando a existência de inventário em excesso ao longo da planta.

Foram levantadas as seguintes informações sobre essa operação, antes e depois da implementação de ações de melhoria: a Capacidade Bruta de Produção (JPH Gross - Jobs per Hour); a Capacidade Líquida de Produção (JPH Net) e o indicador OEE.

Para o cálculo da capacidade bruta de produção, foi levantado o tempo de ciclo das operações; para a determinação da capacidade líquida de produção utilizou-se a média diária de produção dos equipamentos, relacionando-a com o número de horas diárias de trabalho na planta. Adotou-se o valor de 17,4 horas diárias de trabalho, para aquelas operações que operam em dois turnos. A capacidade líquida de produção foi, então, calculada por:

JPH Net = Número de peças produzidas / Número de horas de operação, onde JPH Net representa a capacidade líquida de produção do equipamento. 
Conhecendo-se a capacidade líquida e a capacidade bruta de produção, calculou-se o OEE, para que fosse permitido direcionar ações nos equipamentos:

Passa-se a comentar as análises realizadas sobre as cinco operações de usinagem estudadas, para ilustrar o procedimento adotado. Uma das operações analisadas foi a Operação 320, uma das primeiras operações da linha de usinagem de blocos de motores, e que realizava, em especial, dois furos no bloco utilizando-se de duas ferramentas distintas, denominadas T1 e T2. A ferramenta denominada T1 era responsável pela realização do desbaste, com diâmetro inferior ao diâmetro desejado para o material em questão. Em seguida, realizava-se a troca da ferramenta e utilizava-se a ferramenta T2 para realizar a operação de acabamento. Desta maneira, a operação realizava-se com elevadas perdas de tempo, provocadas pela necessidade da constante troca de ferramentas. Além disso, a necessidade de se usar duas ferramentas distintas elevavam o número de peças a serem controladas e mantidas em estoque, aumentando o grau de complexidade das operações realizadas pelas áreas-suporte.

Percebeu-se uma oportunidade de melhoria com a possibilidade da realização do furo utilizando-se apenas uma ferramenta, que seria responsável pelo desbaste e pelo acabamento do furo. Assim sendo, iniciou-se o estudo e implementou-se uma nova ferramenta com essas características, a qual evitou a necessidade de constantes interrupções no processo para possibilitar sua troca, possibilitando uma usinagem constante, com menores perdas de tempo e reduzindo o tempo de ciclo de usinagem, não afetando a disponibilidade e os indicadores de qualidade e, conseqüentemente, o OEE. Conseguiu-se incremento na produtividade final da máquina, uma vez que se manteve constante o OEE e reduziu-se o tempo de ciclo ganhando-se em capacidade líquida de produção.

A tomada de tempos da Operação 320, no início dos estudos, resultou em um tempo padrão de 54,5 segundos, ou seja, uma capacidade bruta de produção de 66 peças por hora. Assim, a Operação 320 produzia, em média, 783 peças por dia de trabalho e a capacidade líquida era de 45 peças por hora. Posteriormente à aplicação das melhorias propostas, a medição do tempo de ciclo da máquina resultou em uma capacidade bruta de produção exatamente igual àquela anteriormente encontrada. Entretanto, o número de peças produzidas dentro do período de operação aumentou, incrementando assim sua capacidade líquida de produção. A média diária de produção de peças em conformidade com os padrões de qualidade foi de 835 peças, resultando em uma capacidade líquida de produção de 48 peças por hora.

A Operação 325, imediatamente subseqüente à operação 320 na linha de usinagem de blocos de motores, era responsável pela usinagem de diversos pontos da lateral do bloco. Todas as etapas nesta operação eram realizadas utilizando-se apenas uma ferramenta, não abrindo espaço desta maneira para otimizações envolvendo o uso comum de operações em uma mesma ferramenta. 
Após alguns estudos, propôs-se a otimização dos dados de corte, visando a redução no tempo de ciclo de usinagem, tomando-se o cuidado, entretanto, de não comprometer os indicadores de qualidade e disponibilidade da operação para que o OEE não sofresse reduções.

Para otimizar os parâmetros da ferramenta, foi desenvolvida, junto ao fornecedor da mesma, uma nova geometria para o inserto, conseguindo-se a otimização dos dados de corte sem prejuízo da qualidade; reduziu-se o tempo de ciclo da máquina e aumentou-se a capacidade líquida de produção da operação.

O tempo de ciclo era de 65,4 segundos, resultando em uma capacidade bruta de produção de 55 peças por hora. Assim a máquina produzia uma média diária de 661 peças, resultando numa capacidade líquida de produção de 38 peças por hora e OEE de 69\%. Após a ação de melhoria, o tempo de ciclo da máquina reduziu-se para 60 segundos, com capacidade bruta de produção de 60 peças por hora. A produção média diária do equipamento subiu para 748 peças, com capacidade líquida de produção de 43 peças por hora e OEE de 73\%.

A Operação 330 era a seguinte na linha de usinagem, tratando-se de uma árvore de fresas, que realizavam diversas operações de usinagem na face superior do bloco simultaneamente. A ação aqui analisada possuiu por objetivo incremento na qualidade da usinagem, não visando, a princípio, redução no tempo de ciclo e tampouco alterações no OEE. Contudo, incrementando-se a qualidade da operação, reduziram-se os indicadores de perda de peças por rejeição, os re-trabalhos, as paradas da máquina para manutenção e as trocas de ferramentas, o que se refletiu no indicador de eficiência OEE e na capacidade líquida de produção.

Realizou-se uma revisão na geometria da árvore de fresas, alterando-se alguns parâmetros de seu desenho, sem mudar, contudo, os parâmetros de usinagem. Os sensíveis incrementos observados na capacidade líquida de produção podem ser atribuídos ao ganho de qualidade gerado pelo novo desenho da árvore de fresas. O tempo de ciclo deste equipamento antes era 65,3 segundos com uma capacidade bruta de produção de 55 peças por hora. A máquina produzia uma média diária de 661 peças, resultando numa capacidade líquida de produção de 38 peças por hora e OEE de $69 \%$.

Após a implementação da ação de melhoria, o tempo de ciclo da máquina reduziu-se para 60 segundos com a capacidade bruta de produção de 60 peças por hora. A produção média diária do equipamento subiu para 748 peças, resultando em uma capacidade líquida de produção de 43 peças por hora e indicador de eficiência OEE de $73 \%$.

A Operação 350 estava localizada algumas operações à frente das operações até agora analisadas e executava o furo para a galeria de óleo no bloco do motor. Um dos problemas principais da operação 350 era a constante quebra de ferramentas, elevando desta maneira o custo 
com a troca das mesmas, além de gerar drásticas reduções nos valores de disponibilidade da máquina.

A quebra de ferramenta era responsável também por gerar perdas de produção, pois a peça que se encontrava em processo de usinagem sofria danos irreparáveis ocasionados pela quebra da ferramenta. A quebra da ferramenta ocasionava grandes perdas de tempo, visto que a ferramenta era uma broca-canhão, responsável por um furo de grandes dimensões, assim, sua troca era uma operação complexa e havia perdas de tempo para retirada da broca do material em processo. Grandes perdas de disponibilidade, conseqüentemente grandes perdas no OEE estavam associadas a este problema.

Outro grande problema era o tempo de ciclo da máquina, considerado extremamente alto, que afetava sua capacidade bruta de produção. Se, eventualmente, seu indicador de eficiência OEE assumisse valores baixos a capacidade líquida de produção se reduzia proporcionalmente, podendo ocasionar, inclusive, interrupções no fluxo da linha de produção.

Procurou-se direcionar esforços visando à eliminação, ou a redução da ocorrência de quebras de ferramentas, contando com auxílio de empresa terceirizada contratada para realizar o suprimento das ferramentas em toda a planta. Com o auxílio do fornecedor de ferramentas para esta máquina, desenvolveu-se uma nova geometria da ferramenta, sem, entretanto, alterar os parâmetros de usinagem, visando o aumento da vida útil e eliminação das quebras.

Reduziu-se, assim, o custo com trocas de ferramentas, o tempo ocioso da máquina, com conseqüente incremento de disponibilidade e, indiretamente, gerou-se ganhos em qualidade do produto, inclusive afetando o OEE. O equipamento apresentava um tempo de ciclo de 63,15 segundos e uma capacidade bruta de produção de 57 peças por hora; além de uma média diária de produção de 678.6 peças, resultando numa capacidade líquida de produção de 39 peças por hora. Com as modificações sugeridas, a tomada de tempos da operação resultou em tempos de ciclo iguais e uma capacidade bruta de produção igual também, mas a máquina passou a produzir uma média de 731 peças por dia, sua capacidade líquida apresentou um crescimento atingindo 42 peças por hora e seu indicador OEE passou para $75 \%$.

Na seqüência, passou-se à Operação 370, a qual era historicamente a operação gargalo da linha de usinagem de blocos de motores, sendo considerada uma das máquinas mais críticas de toda a planta da fábrica de motores, devido às suas constantes quebras e conseqüentes paradas na produção. Tratava-se de uma máquina transfer, de elevada idade, logo com constantes necessidades de manutenção - preventiva e corretiva. Sua disponibilidade sempre foi alvo de inúmeras ações de engenharia, assim como de ações visando a redução em seu tempo de ciclo e tentando minimizar os efeitos de suas constantes paradas. 
A Operação 370 era responsável pela realização de uma série de furos no bloco. Essa peça ingressava no equipamento conduzida por um transportador que a locomovia ao longo de toda a linha, ela sofria as furações em uma das faces, a máquina então a manipulava, de maneira que as outras faces sofriam a usinagem sucessivamente. Desta maneira, o bloco estava em constante movimentação dentro da operação 370 e era um dos fatores críticos de sua disponibilidade.

Em eventuais falhas dos tombadores da máquina, que eram os responsáveis pela manipulação do bloco, o mesmo caia sobre o transportador e, sendo ele extremamente pesado (cerca de $30 \mathrm{~kg}$ ), na maioria das vezes quebra-se o transportador. Sendo assim, era necessária uma intervenção extremamente complexa na operação, abrindo-se o equipamento para efetuar o reparo do transportador antes que a produção seja continuada. Como não existiam máquinas em paralelo que realizassem a mesma operação em eventuais falhas, toda a produção ficava comprometida, às vezes por cerca de oito a nove horas.

Desta maneira, as ações de engenharia foram direcionadas de maneira a evitar a queda do bloco que se encontrava em processo de usinagem por ser uma falha de elevado Tempo Médio para Reparo (MTTR - Medium Time to Repair). Evitando-se a ocorrência deste tipo de problema, incrementava-se a disponibilidade do equipamento.

Realizou-se então um plano de revisão robusto de manutenções preventivas dos tombadores da Operação 370, analisando-se todos os seus parâmetros e adotando intervalos de manutenção extremamente rígidos, de maneira que fosse possível à Engenharia, a qualquer momento, conhecer a situação dos mesmos, para evitar a falha antes que ela ocorresse. Outras propostas foram efetivadas com respeito a esta máquina, como a implementação de ações que visassem incrementar a vida útil do mandril, onde sempre ocorriam danos devido à projeção de cavacos sobre o mesmo.

Assim, o equipamento apresentava antes uma média diária de produção de 643,8 peças, com uma capacidade líquida de 37 peças por hora e OEE de 70\%. Com as mudanças, o equipamento apresentou um maior tempo necessário para a execução de suas tarefas, apresentando um tempo de ciclo de 72 segundos e capacidade bruta de produção de 50 peças por hora, mas sua média diária de produção subiu para 670 peças por hora, resultando em uma capacidade líquida de produção de 38 peças por hora.

A Operação 370, como dito anteriormente, era considerada o gargalo de toda a linha de fabricação de blocos da fábrica estudada, sendo assim, não se permitia em hipótese alguma, perdas de produção, que não os provocados por motivos de quebra (falha) no equipamento. Procurava-se sempre utilizar todos os momentos disponíveis para sua operação, assim, optou-se, nesta operação, por disponibilizar uma área de estoque intermediário entre operações, composto por blocos de motores semibeneficiados, aptos a ingressar na Operação 370. 
Percebeu-se que, agora, eventuais problemas com operações anteriores à 370 não causariam a imediata parada no seu funcionamento, o que seria extremamente grave, por esta possuir um tempo de ciclo alto e capacidade de produção extremamente baixa. A existência de pulmões entre as operações penaliza a fábrica por acarretar inventário em excesso, entretanto, em determinados casos, como foi este último, pode-se justificar sua adoção visando incremento na produtividade da linha através do pleno uso dos equipamentos, mesmo em condições adversas.

Resumindo os resultados obtidos, a Figura 1 apresenta a evolução da produção total da linha de usinagem de blocos de motores medida pelo número de blocos produzidos no final da linha, expressando, também, a evolução da produtividade da linha, uma vez que os recursos se mantiveram inalterados. Ela reflete o resultado de uma série de ações implementadas isoladamente, ao longo da linha e entre as operações. Percebe-se uma clara tendência de incremento na produtividade da linha. Os dados são referentes a 22 semanas, incluindo o período em que foram implementadas as ações de melhoria.

Figura 1 - Evolução semanal da produção da linha de usinagem de blocos de motores

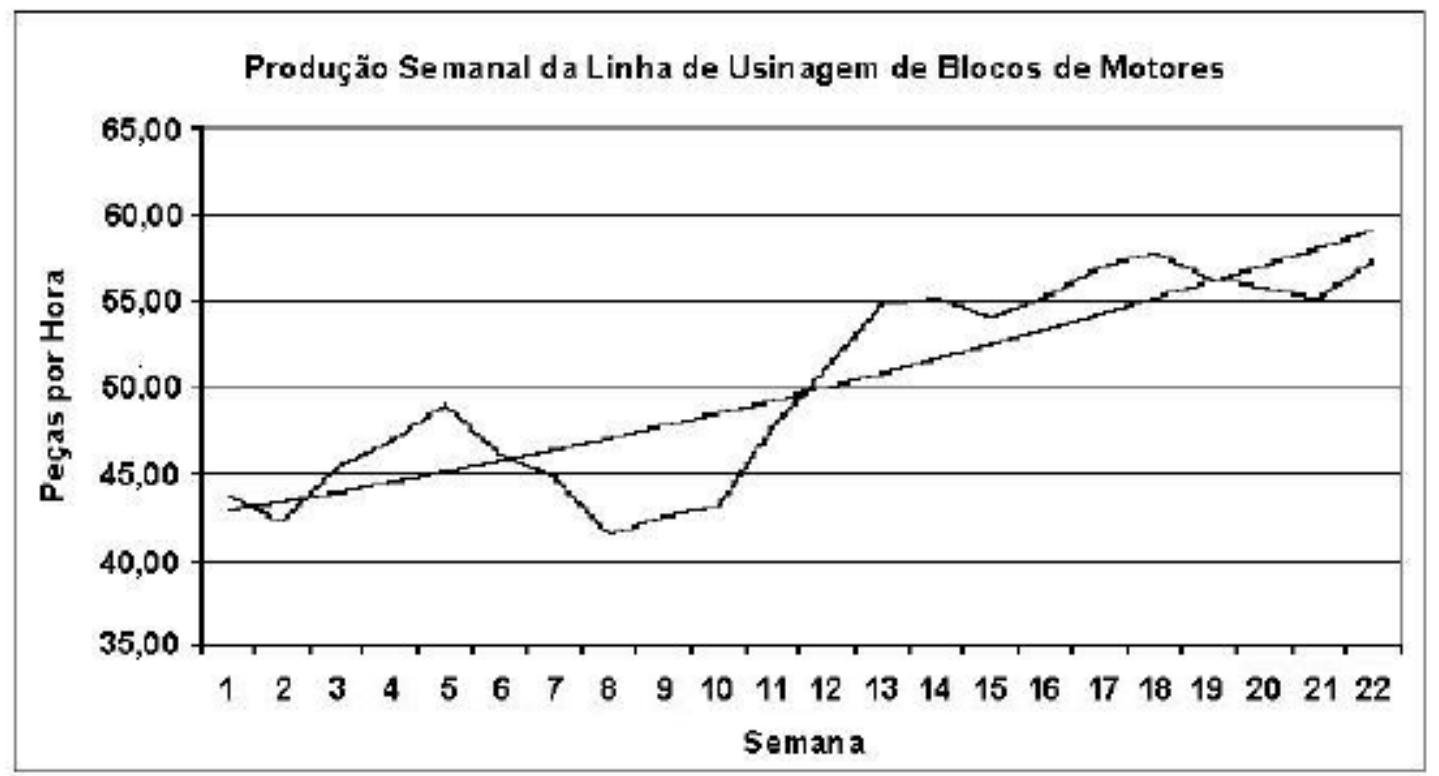

Fonte: divulgação não autorizada

\section{Conclusões}

A TOC apresentou-se como uma proposta interessante para a análise de linhas de fabricação baseada nas operações ou atividades que demandem um maior tempo para sua execução, restringindo dessa maneira a produção como um todo. Como parte da gama de ferramentas oferecidas pela Engenharia de Produção, encontrou-se no Indicador de Eficiência Global do Equipamento - OEE um método extremamente útil para a análise do desempenho de linhas de fabricação. O OEE foi útil para identificar o gargalo no caso de linhas de produção em série, 
possibilitando, ainda, a obtenção de uma visão global do processo por disponibilizar num único indicador as informações acerca da disponibilidade do equipamento, qualidade, e eficiência.

Percebeu-se neste trabalho que as pequenas ações direcionadas aos equipamentos, realizadas seguindo os conceitos de melhoria contínua (pequenas, mas constantes implementações de pequenas melhorias) surtiram efeito consideravelmente positivo nos níveis de produção da linha de fabricação, em um tempo relativamente curto (seis meses).

Pode-se perceber que incrementos na capacidade produtiva de linhas de fabricação que estão próximas do limite são extremamente valiosos e importantes. A produção da linha de motores passou de cerca de 43 peças por hora, no final do ano anterior, para quase 60 peças por hora, no final do primeiro semestre do ano seguinte. Trata-se de um ganho considerável e os resultados deste trabalho comprovam a necessidade da constante busca por melhores resultados e melhores ações dentro da indústria. Por fim, registra-se a oportunidade de inúmeros trabalhos futuros, envolvendo o direcionamento de ações de melhoria junto aos equipamentos analisados.

\begin{abstract}
This paper introduces and utilizes the concept of the Overall Equipment Effectiveness (OEE), committed to the Theory of Constraints (TOC) and Kaizen techniques, as an instrument for analysis and selection of improvement actions in manufacture lines. This methodology was used in a multinational automotive engine factory, localized in the Vale do Paraíba region, interior of São Paulo state (Brazil). Besides the operations performance indicators evolution, his study also introduced the production evolution of the complete manufacture line. The satisfactory results achieved clear denote the validity of the committed use of these techniques in the Production Engineering.
\end{abstract}

Key-words: Overall Equipment Effectiveness, Theory of Constraints, Kaizen.

\title{
Referências
}

CONTADOR, J.C. Gestão de Operações: A Engenharia de Produção a Serviço da Modernização da Empresa. São Paulo: Edgard Blücher, 1997.

COX III, J.F. \& SPENCER, M. S. Manual da Teoria das Restrições. Porto Alegre: Bookman, 2002.

GOLDRATT, E. \& COX, J. A Meta: um processo de aprimoramento contínuo. São Paulo: Educator, 1997.

HANSEN, R. C. Overall Equipment Effectiveness. $1^{\text {st }}$. ed. New York: Industrial Press, 2002.

HOBBS, D. Lean Manufacturing Implementation: A Complete Execution Manual for Any Size Manufacturer. Florida: J. Ross Publishing, 2003.

Kaizen Tools. Disponível em: <http://www.gembakaizen.com>. Acesso em 04 nov. 2003. 
MAURER, R. One Small Step Can Change Your Life: The Kaizen Way. New York: Workman Publishing, 2004.

SLACK, N. et al. Administração da Produção. 2a. ed. São Paulo: Atlas, 2002.

The Fast Guide to OEE. Disponível em: <http://www.oee.com/fasttrack_oee.html>. Acesso em 15 jul. 2003.

\section{Dados do autor:}

Artur Henrique Moellmann

Gerente de Planejamento

Mectron Eng., Ind. e Com. - São José dos Campos - SP -

e-mail:ahmoellmann@terra.com.br

www.mectron.com.br

Mestrando em Engenharia Mecânica - Linha de Pesquisa em Engenharia de Produção

Universidade Estadual Paulista (UNESP) - Campus de Guaratinguetá - Departamento de Produção Av. Ariberto Pereira da Cunha, 333 Guaratinguetá - SP CEP: 12516-410

Fone: (12) 2139-3526

Recebido para publicação em: 01/12/2005

Aceito para publicação em: 05/02/2006 